\title{
El documento y las nuevas tecnologías: hacia una definición integradora
}

\author{
Juan Antonio Martínez Comeche \\ Escuela Universitaria de Biblioteconomía y \\ D ocumentación, Universidad Complutense de Madrid \\ E-mail:comeche@ caelo.eubd.ucm.es
}

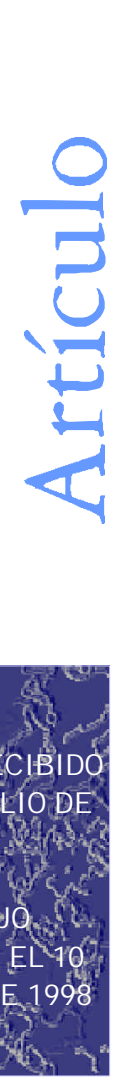

\section{RESUMEN}

Partiendo de la base de que los estudiosos deben analizar las consecuencias y repercusiones de esos progresos efectuados por la humanidad en sus áreas de conocimiento respectivas, observando la medida en la que pueden asimilarse los paradigmas conocidos y manejados hasta entonces, y de que las nuevas tecnologías de la información sin duda han repercutido notablemente en el quehacer documental, tanto desde la prisma teórico como práctico, en este trabajo se intenta analizar las innovaciones relevantes que las nuevas tecnologías introducen en la concepción clásica del documento, tratanto de integrarlos en una primera aproximación al paradigma comunicativo clásico, e incorporando al mismo tiempo las modificaciones que conllevan.

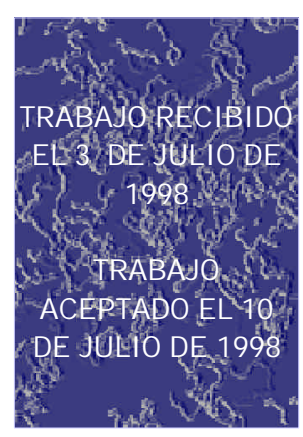

\section{ABSTRACT}

THE DOCUMENT AND NEW TECHNOLOGIES:

TOWARDS AN INTEGRATED DEFINTION

JuAn Antonio MaRtíneZ-CoMEche

Scholars should analyze the consequences and repercussions of progress achieved by humanity in their respective knowledge fields, observing up to what point known and well used paradigms can beassimilated. New information technologies without a doubt have had notable repercussions in the everyday work of the documentalist., from both the theoretical and the practical angles. The present study attempts to analyze the relevant innovations that the new technologies have introduced into the classic conception of the document, trying to integrate these in a first approximation to the classic paradigm of communication and at the same time incorporating the required modifications..

\section{INTRODUCCIÓN}

Ciempre que distintos procedimientos y técnicas novedosas se insertan en una sociedad se ven afectados, en mayor o menor grado, la forma de vida y costumbres de esa sociedad y también su quehacer científico. Los estudiosos deben analizar las consecuencias y repercusiones de esos progresos efectuados por la humanidad en 


\section{2}

sus respectivas áreas de conocimiento, observando en qué medida pueden asimilarse a los paradigmas conocidos y manejados hasta entonces.

Las nuevas tecnologías de la información sin duda han repercutido notablemente en el quehacer documental, tanto desde el prisma teórico como práctico. Baste señalar aquí las palabras de Bill Gates, cuando afirma que "el aspecto más excitante de la documentación digital es la redefinición del documento mismo".

En este trabajo intento analizar las transformaciones relevantes que las nuevas tecnologías introducen en la concepción clásica de documento, tratando de integrarlas en una primera aproximación al paradigma comunicativo clásico, e incorporando al mismo tiempo las modificaciones que conllevan.

\section{SIGN O, MEN SAJE Y DOCUMENTO}

Como es sabido, Peirce obtuvo tres clases de signos en función de su relación con la realidad:

A. Ícono. El signo icónico representa el objeto de la realidad o sus propiedades mediante una relación de semejanza, de manera que la relación signo/ referente es inmediata (fotografía, retrato...).

B. Indicio. El indicio presenta una relación causal entre el signo y el referente, de forma que el signo representa al objeto porque éste origina aquél (humo, signo indicial del fuego que lo origina).

C. Símbolo. El símbolo implica una relación signo/ referente convencional y arbitraria (los signos lingüísticos, por ejemplo).

Conviene hacer hincapié en que todos estos entes (fotografía, humo y palabra) no configuran por sí mismos íconos, indicios y símbolos. D esde el punto de vista de la semiótica, en palabras de Sebeok:

[...]la propiedad de ser signo no es una propiedad natural que pueda ser examinada y confirmada, sino una propiedad que se otorga a los objetos, ya sean naturales 0 artificiales, a través del tipo de uso que se haga de ellos. 1

Podemos concluir, en definitiva, que es el receptor quien decide cuándo algo es un signo y qué clase de signo es. Por este motivo, la semiótica impone dos condiciones para que un signo se convierta en señal, que agrupada junto a otras señales conforme a unas reglas concretas de combinación, configurarán mensajes:

1. Poseer una finalidad comunicativa; es decir, ser empleado para comunicar algo.

2. Poseer un referente reconocible por el receptor y compartido con el emisor.

Ahora bien, un receptor puede decidir otorgar a cualquier ente una finalidad comunicativa ("ese objeto, sea cual sea, le dice algo"). Por otra parte, puesto que ha sido facultado para ello desde un enfoque semiótico, puede "construir" un sig-

1 T. A. Sebeok. (ed.). Encyclopedic D ictionary of Semiotics. Berlín: Mouton de G ruyter, 1994, vol. 1, p. 18. Cit. Por Buckland, Michael K. "What is a "D ocument"?" Jamal oftheAmeicanSocidyforIn formationSaiene, 1997, 48(9): 807. 
no a raíz de un objeto cualquiera, asimismo está capacitado para decidir si lo considerará signo icónico, simbólico o indicial. Sin embargo, conforme a la segunda condición expuesta, sólo debemos considerar como mensajes (mensajes, en consecuencia, inicialmente objeto de la ciencia de la Documentación) a aquellos signos que posean un referente compartido por emisor y receptor, reconocible como tal por éste.

En lo que afecta a la comunicación entre personas (emisor y receptor humanos), esta segunda condición es altamente restrictiva, al imponer el empleo de signos simbólicos (signos lingǘsticos, por excelencia) compartidos por ambos.

El caso más problemático lo plantean los objetos físicos cuando actúan como emisores, siendo humano el receptor. El caso más habitual es el de una persona que observa un objeto físico. Conforme a la teoría semiótica, si se elimina la posibilidad de que el objeto sea un símbolo - un semáforo, por ejemplo-, pues estaríamos en circunstancias semejantes a las señaladas en el párrafo anterior, un receptor puede originar a raíz de dicho objeto un signo icónico o un signo indicial. Las cuestiones que debemos dilucidar aquí son dos:

1. Cuándo existe mensaje propiamente dicho, y cuándo no.

2. Cuál es el referente del mensaje, en caso de existir.

El proceso, cuando el receptor genera un signo icónico como cuando genera un signo indicial, presenta unas fases iniciales idénticas:

A. La luz se refleja en el objeto (el humo, por ejemplo) y estimula la retina del receptor.

B. El nervio óptico "traduce" esta señal, que se transmite hasta la zona correspondiente del cerebro.

C. Allí, existe una representación visual del objeto.

D . Nos encontramos ante una cadena de procesos mentales que, en muchos casos (se excluye aquí la circunstancia de que sea incapaz de denominarlo, por problemas físicos, por desconocimiento o porque previamente no hubiese visto un objeto igual), concluye con la representación mental del nombre del objeto: "humo".

A partir de este momento, la generación de un signo icónico o indicial implica fases posteriores distintas:

A. En el caso de un ícono, el receptor genera como referente todos los entes de la realidad que posean las propiedades que otorgamos al "humo".

B. En el caso de un indicio, el receptor genera como referente todos los entes de la rea lidad que causan el "humo"; aunque pueden ser de naturaleza muy variable (hoguera, cigarrillo, en general algo que arde...; por lo que se presenta la dificultad de restringir unívocamente el referente en los indicios, que dependen siempre del receptor, las circunstancias...). En todo caso es posible englobarlos bajo la denominación "fuego".

Si nos ajustamos a la segunda condición impuesta a los signos para que puedan constituir mensajes, debe ser el emisor (en nuestro caso, el propio objeto físico) 


\section{InvetigaaónBiblidtedógica v. 12 No. 25 julio/ diciembre de 1998}

quien posea un referente que pueda ser compartido y reconocido como tal por el receptor.

Cuando el receptor genera un ícono, hemos de reconocer que en cualquier circunstancia, y sea cual sea el objeto/ emisor, se produce un mensaje unívoco, único. En efecto, siendo todo objeto ícono de sí mismo por cuanto se representa de manera inmediata, el referente "emitido" por dicho objeto es él mismo, lo que es y cómo es.

A su vez, puesto que este referente (el propio objeto) puede ser compartido y reconocido como tal por cualquier receptor, podemos deducir que todo objeto físico origina - si no explícitamente, sí de manera implícita siempre- una señal única que, a su vez, conforma un mensaje elemental unívoco y exclusivo que cualquier receptor puede hacer explícito: el de su mera existencia, lo que es y cómo es. En el ejemplo expuesto, ese mensaje es "humo".

En cambio, cuando el receptor genera un indicio, no es posible delimitar unívocamente el mensaje transmitido; porque al no establecerse la relación entre el signo y el referente inmediato, sino a través de una relación causal, el receptor adquiere un grado de libertad mayor a la hora de generar el referente, que ya no es único sino múltiple: hoguera, cigarrillo, incendio...; en consecuencia, el mensaje no es unívoco y exclusivo.

Se podría argumentar que existe la posibilidad de englobar todos esos mensajes en uno solo: "fuego", "algo que arde"... Ello supondría una reducción peligrosa desde un punto de vista teórico, pues implicaría el análisis previo de todas las posibles circunstancias en que pudiese situarse el objeto físico y el estudio de todos los posibles referentes generados por todos los receptores, para construir posteriormente un hipotético referente común, cuya existencia es más que improbable. $\mathrm{Si}$ deseamos establecer una ciencia documental con principios sólidos, y no con pilares vagos y de difícil manejo teórico y práctico, esta solución no parece muy aconsejable.

Al hilo de esta discusión, conviene exponer un peligro semejante que acecha cuando los profesionales de la documentación se enfrentan a mensajes simbólicos, por ejemplo, un texto escrito. Es sabido que pueden producirse variaciones relevantes en la recepción; relativas al referente que el emisor deseaba transmitir, por lo que:

[...] no es posible garantizar en ningún caso la inmutabilidad del mensaje en la fase de recepción[...] Sin duda, el receptor procura reconstruir en la medida de lo posible el referente que portaba el mensaje original. Pero hemos de reconocer que la comprensión en identidad de términos es una imposición demasiado exigente en la comunicación humana. ${ }^{2}$

Platón expresó este fenómeno con las siguientes palabras:

2 J. A. Martínez Comeche. Teeńa dela informacóndbametal ydelas insituriones doumetales Madrid: Síntesis, 1995, p. 45. 
El que piensa que al dejar un arte por escrito, y, de la misma manera, el quelo recibe, deja algo claro y firme por el hecho de estar en letras, rebosa ingenuidad. ${ }^{3}$

Este fenómeno complejo relacionado con la lectura alude a que, en la recepción, el receptor no se limita a reproducir el mensaje, sino que en realidad lo interpreta de una forma personal e individualizada; "interpretación condicionada por sus conocimientos previos sobre el tema, su formación cultural, su capacidad intelectual, la atención prestada al interlocutor, etcétera." 4

A hora bien, esta interpretación singular realizada por cada receptor de un texto idéntico no impide que todos ellos, sin excepción, deban representar, de modo previo, mental y estrictamente el mensaje escrito. Dicha representación mental, a su vez, implica un referente inmediato conforme al valor simbólico impuesto por el idioma (o lengua) compartido por emisor y receptor. Este referente inmediato es el que garantiza la existencia de un mensaje único de carácter simbólico.

La recepción, sin embargo, constituye un proceso muy complejo que no se detiene siempre en la reconstrucción de ese referente inmediato, de manera que cada receptor puede, a partir de ahí, generar posteriores referentes conforme a las variables y condicionantes expresadas con anterioridad. De ahí la denominación de interpretación que recibe esta fase añadida, expresiva de su naturaleza y del momento en que se efectúa. Dicho de otra manera, la frase en castellano "Pedro tiene fiebre" posee un referente inmediato único para los hablantes de español de una determinada zona (evitamos así significados dialectales, usos específicos de un país frente a los otros hispanoparlantes, etcétera): "una persona, cuyo nombre de pila es Pedro, posee una temperatura corporal superior a la habitual en el ser humano", y en consecuencia, constituye un mensaje unívoco de carácter simbólico. D espués, cada receptor está facultado para interpretar la verdad o falsedad del mensaje (pues curiosamente Pedro tenía un examen de matemáticas), o generar otro referente final distinto ("Pedro está actuando alocadamente o de manera no habitual en él" etcétera), dado el tono empleado por el emisor. Estas interpretaciones, sin embargo, pasan por la reconstrucción inicial del mensaje inmediato y de su correspondiente referente.

De manera consciente o inconsciente, los bibliotecarios y profesionales de la documentación, durante milenios, han manipulado y tratado exclusivamente estos "mensajes neutrales", excluyendo de su quehacer las posibles interpretaciones que los lectores pudiesen establecer a raíz de ellos.

Esta diferenciación entre referente inmediato y referentes posteriores o mediatos puede extenderse, sin variaciones de relevancia, al proceso de generación de un signo icónico y de un indicio. Si observamos las fases iniciales comunes (A-D),

3 Platón. Diálogs, III: Felón, Banquate, Feero Traducciones, introducciones y notas por C. García Gual, M. Martínez Hernández, E. Lledó. Madrid: Gredos, 1992, p. 405.

4 J. A. Martínez Comeche. Op at, p. 45. 
comprobaremos que en ambos casos se concluye con la representación mental del nombre del objeto ("humo"). Dicha representación mental implica la aparición de un referente inmediato, esto es, "todos los entes de la realidad que posean las propiedades que otorgamos al humo". Este referente inmediato no es otro que el referente icónico, como podemos comprobar.

Contemplado así, podemos deducir que cuando un receptor genera un signo indicial, mentalmente reproduce -en primera instancia- el signo icónico correspondiente al objeto que está observando (paso previo imprescindible: primero ha de contemplar el ente físico para poder relacionarlo con la causa que lo originó), y en seguida interpretar un referente mediato, obtenido en este caso mediante la aplicación de una relación causal.

Al haber reducido, por una parte, el proceso de recepción de todo mensaje a la creación de un "referente inmediato" y a una fase posterior de interpretación que permite generar otros "referentes mediatos"; y al considerar, por otra parte, las ventajas teóricas y prácticas que para la ciencia documental presenta la consideración de mensajes con referentes únicos (piénsese en la imposibilidad de analizar un mensaje indicial, tratando de representarlo como tal indicio, es decir, debiendo considerar todos sus posibles referentes), consideramos que un documento debe estar formado exclusivamente por mensajes icónicos y simbólicos, pues de acuerdo con las concepciones de los signos que los conforman, generan referentes únicos, compartidos en cualquier circunstancia por todo receptor.

Las nuevas tecnologías, mediante los denominados hipertextos, muestran cómo un emisor puede no desear transmitir un único mensaje que remita a un referente concreto. Los especialistas han expresado en ocasiones su deseo de que, en los hipertextos, "se dejen suficientemente abiertas las vías a interpretaciones distintas de la del autor, aun sobre la misma base informativa; y ello con el fin de evitar que de forma implícita o subliminal, por el solo hecho de establecer ligaduras entre ciertas piezas de información o por la forma de presentarlas, se pasen de contrabando o se 'fijen' determinadas interpretaciones." 5

En efecto, los enlaces o ligaduras entre nodos no son neutrales, sino altamente significativos a efectos de configurar un mensaje. Este fenómeno puede observarse con claridad si tomamos, por ejemplo, un ensayo concebido linealmente: en su integridad configura un mensaje que remite a un referente concreto alusivo a la opinión del autor sobre el tema del ensayo. Este mismo texto puede adoptar una estructura hipertextual sin que en nada se vea afectado el mensaje que transmite: bastará construir nodos con cada capítulo, y establecer enlaces correlativos entre ellos: $\mathrm{A} \rightarrow \mathrm{B} \rightarrow \mathrm{C} \rightarrow \ldots \rightarrow \mathrm{L}$ (último capítulo).

5 I. Canals Cabiró. "Introducción al hipertexto como herramienta general de información. Concepto, sistemas y problemática”. ReistaEspañda deDoumetaaión Cietífica, 1990, 13(2): 704. 
Ahora bien, si tomamos esos nodos/ capítulos y los aislamos por completo, permitiendo a cualquier receptor el acceso, en el orden en que él desee (presentándolos en pantalla en un círculo, de manera que la posición de cada uno de ellos sea idéntica a los demás), a cualquier nodo/ capítulo (este mismo efecto puede conseguirse permitiendo el acceso, desde cualquier nodo, a todos los demás), convendremos en que el mensaje original ya no existe, como tampoco el referente alusivo a la opinión del autor. Este efecto es más eficaz en la medida en que fragmentemos más los propios nodos (capítulos, epígrafes, párrafos, frases).

Los hipertextos que puedan elaborarse se hallan entre estos dos extremos expuestos, sin solución de continuidad. En el primer caso nos hallamos ante un texto lineal "clásico" con un único mensaje y su referente inmediato correspondiente. En el segundo caso nos encontramos con un hipertexto "puro" que carece de mensaje global, porque su autor ha querido expresamente que ese mensaje (con su referente) no aparezca, dejando al receptor que halle y cree sus propias conclusiones a partir de los nodos que componen el documento hipertextual.

A la postre, ello implica que el receptor debe interpretar de manera individual y personal el conjunto del documento a partir de sus componentes o nodos (el fenómeno por el cual un receptor lee algunos nodos, no todos, en nada se diferencia del lector de un capítulo o de un párrafo de un libro. En ambos casos se accede a mensajes parciales, con sus correspondientes referentes).

En resumen, el proceso de recepción es idéntico al enunciado del principio: una primera fase que implica la reconstrucción de referentes inmediatos, con la salvedad de que ahora no es un único mensaje, sino tantos como nodos posea el hipertexto; y una segunda fase de interpretación en la que el receptor establece relaciones de muy variada naturaleza entre esos mensajes (conforme a sus conocimientos previos sobre el tema, su formación cultural, su capacidad intelectual, la atención prestada, etcétera), generando otros referentes posteriores o mediatos, coincidentes o no con la opinión del autor sobre el tema.

En definitiva, la estructura hipertextual presenta dos características esenciales:

1ํㅡ D escomposición del documento en varios mensajes, cada uno de ellos con su referente inmediato correspondiente (simbólico o icónico).

$2^{\text {a }}$ Concesión de mayor relevancia alafase deinterpretación personal existente en la recepción de cualquier mensaje.

Estas características, conviene hacer hincapié en ello, aunque distinguen el documento "clásico" del hipertextual, se ajustan bien al mismo modelo de comunicación y recepción visto inicialmente.

En consecuencia, en lo que afecta a la definición del documento, podemos concebir éste como "mensaje o mensajes icónicos o simbólicos". 


\section{DOCUMENTO Y SOPORTE}

Cualquier mensaje precisa, para ser transmitido de un soporte. Aunque, como acabamos de mostrar, el documento puede reducirse a la noción de mensaje 0 conjunto de ellos, resulta obvio que no todo mensaje es un documento (una comunicación verbal directa, por ejemplo). D e ello se deduce que la particularidad del documento como mensaje no puede consistir en la propia existencia del soporte, pues todos los mensajes lo necesitan para ser transmitidos, sean documentos o no. La primera consecuencia, pues, desde el punto de vista de la conceptuación del documento, es la insuficiencia teórica (por redundancia) de una definición-tipo como: "mensaje registrado", "información registrada", etcétera.

El documento configura una variante del mensaje desde el momento en que se le exige al soporte una característica peculiar que no cumplen todos. Esta característica tiene lógicamente relación con esa capacidad de actualización del pasado que la faculta para cumplir la misión cultural fundamental para la que fue creada por nuestros antepasados: el atesoramiento y comunicación intemporal de todo conocimiento generado por el ser humano. Dicho de otra manera, a la ciencia documental no le interesan los mensajes cuyo valor informativo no pueda ser renovado en cualquier momento (es el caso de los mensajes orales, instantáneos por naturaleza).

En resumen, el hecho de registrar un mensaje en un soporte faculta la aparición de documentos, pero no garantiza su existencia. Es preciso, además, que ese soporte (energético o material) garantice la perpetuación del mensaje incorporado, prolongando indefinidamente el acceso al contenido informativo que entraña.

Esta característica peculiar del soporte, imprescindible para caracterizar el documento en la ciencia documental, ha sido plasmada por los estudiosos de forma diversa. Robert Escarpit, por ejemplo, la denomina estabilidad del soporte, siendo esta propiedad la que dota al documento de independencia temporal: "[el documento] no es ya un suceso inscrito en el transcurso del tiempo, sino un soporte material del rasgo que puede ser conservado, transportado y reproducido." ${ }^{6}$ López Yepes, en cambio, ha optado recientemente por señalar de manera explícita esta propiedad y otras del soporte en su definición de documento: "El documento en general puede definirse como la objetivación de un mensaje en un soporte físico transmisible y transformable en el espacio y en el tiempo[...]"7

La facilidad con que nuestros archivos de la computadora pueden difundirse a través de redes telemáticas de alcance mundial ha originado la sensación de que los textos, imágenes y sonidos que pueden contener poseen esta propiedad gra-

- 6 R. Escarpit. Temáa geneal delainformaiónydela commicaaón Barcelona: Icaria, 1977, p. 120.

7 J. López Y epes. "Hombre y documento. D el homosapiensal homodoumetator". Conferencia pronunciada en Ibesid98 (Zaragoza, Universidad de Zaragoza, 7 de mayo de 1998). En prensa. 
cias a que se han desembarazado de su soporte. Nicholas Negroponte lo ha expresado así:

En las autopistas de lainformación circulan, sin peso y ala velocidad de la luz, bits de todo el globo [...] En las empresas deinformación y entretenimiento, bits y átomos se confunden a menudo. La edición de un libro ¿pertenece al negocio de la distribución de información (bits) o al de la manufactura (átomos)? La respuesta, desde un punto de vista histórico, es que forma parte de ambos, pero esto no tardará en cambiar a medida que las aplicaciones de lainformación vayan extendiéndosey sean de fácil empleo. 8

Como es sabido, estos archivos, mientras están grabados en un disquete o en el disco duro, poseen su soporte como cualquier otro mensaje registrado. Pero, iy si ese archivo no estuviese grabado, limitándose a "viajar" constantemente por la red?

Es fácil comprobar que esta aparente "volatilidad" no exime del principio teórico según el cual "todo mensaje necesita de un soporte para difundirse", aunque presenta unas características peculiares que conviene reseñar.

Supongamos que escribo un texto en la computadora sin archivarlo. Ahí ese texto se halla en forma de una señal eléctrica:

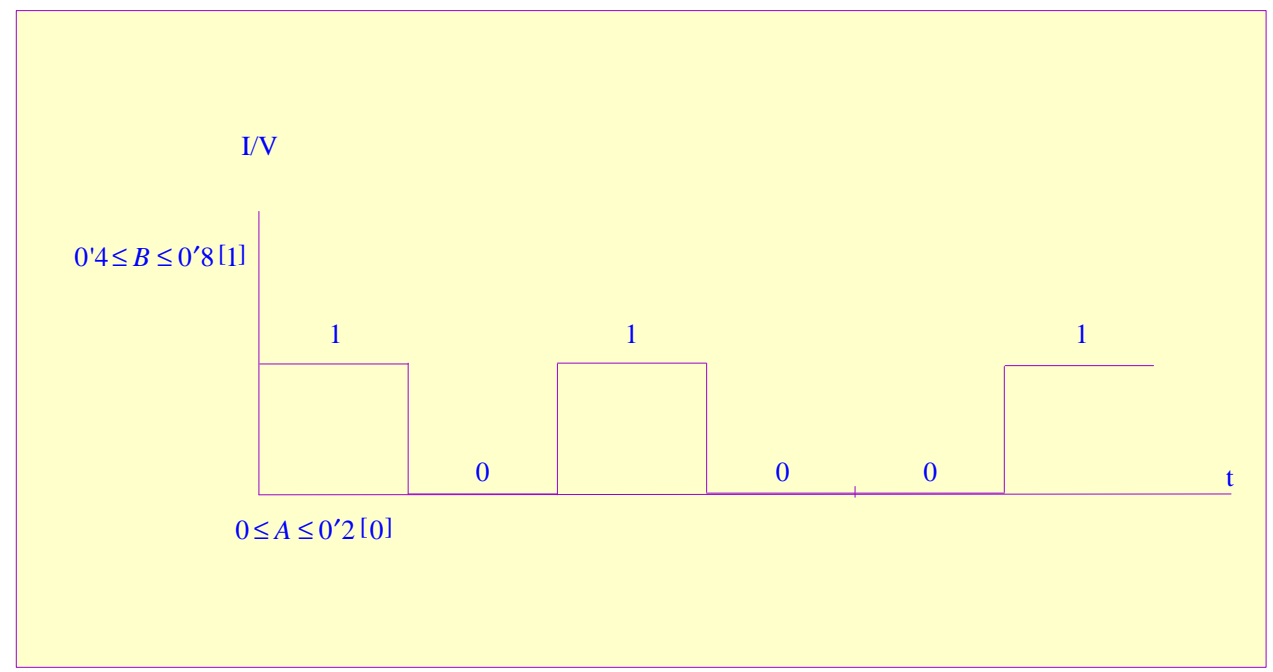

Y posee como soporte la circuitería interna de la computadora.

8 N. Negroponte. El mundodigtal. Barcelona: Edic. B., 1995, p. 26-27. 


\section{InnestigacónBiblictedógía v. 12 No. 25 julio/ diciembre de 1998}

Supongamos también que, previamente a la conexión a una red de transmisión de datos, el texto es enviado a través de la línea telefónica. Para ello la compputadora deberá disponer de un modem que transformará el mensaje digital (dos únicos valores de la señal) en un mensaje analógico (esto es, la señal presenta muchos valores):

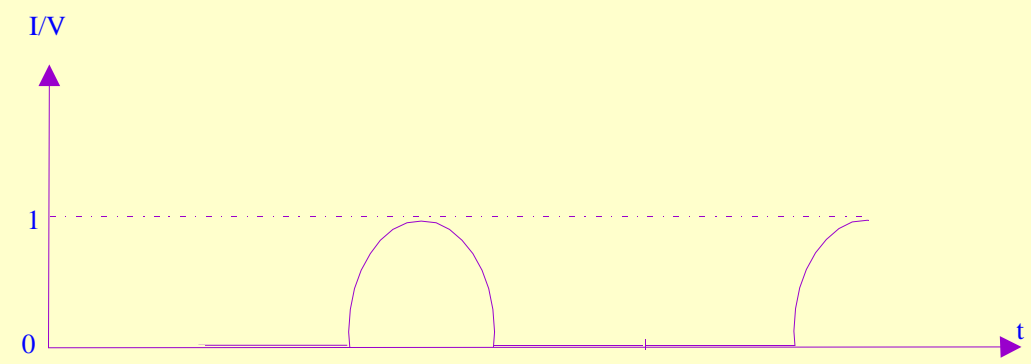

A hora también se ha modificado el soporte de esta señal, siendo, por ejemplo, el hilo de cobre habitual en la red telefónica.

A su vez, cuando se conecte a una red local de transmisión de datos de gran capacidad, otro modem volverá a modificar la forma del mensaje (de nuevo digital). El soporte dejará de ser el hilo de cobre y ahora será la fibra óptica:

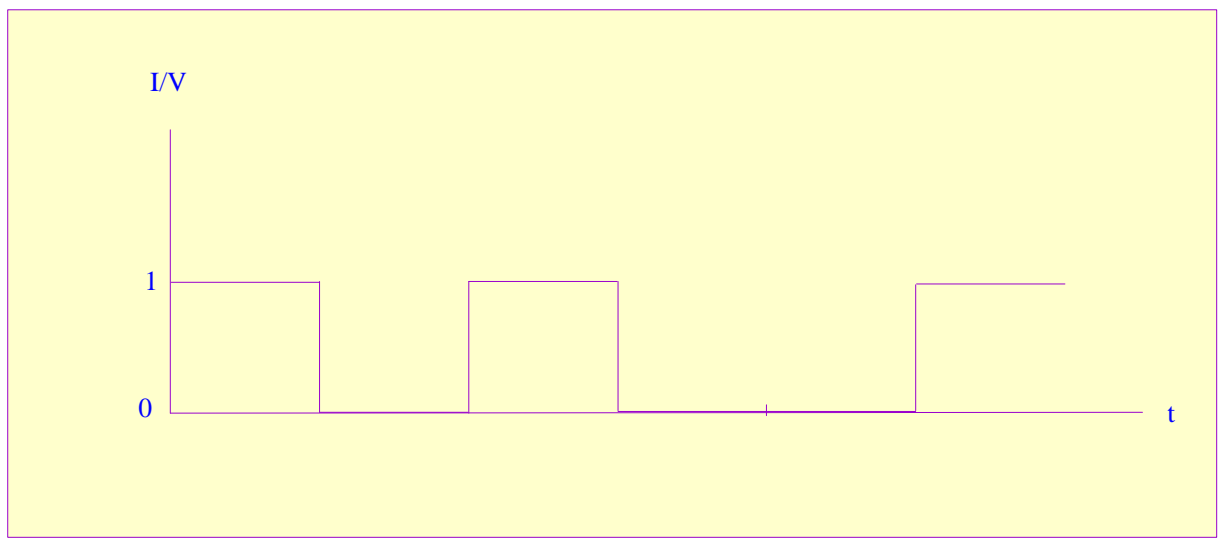

Supongamos ahora que esa red de transmisión de datos está conectada con otra red de datos situada en otro continente, y que la conexión se establece vía satélite. En ese caso, las tecnologías de la telecomunicación son capaces de volver a transformar el mensaje, dotándole de una nueva forma: señal electromagnética (median- 
te la creación de un campo electromagnético); esta señal electromagnética, a través de una variación de su frecuencia, amplitud o fase, puede reproducir bien tanto una señal analógica como digital. El soporte habitual de esa señal electromagnética es el vacío. De hecho, las señales electromagnéticas se difunden mucho mejor en el vacío que en la atmósfera. En resumen:

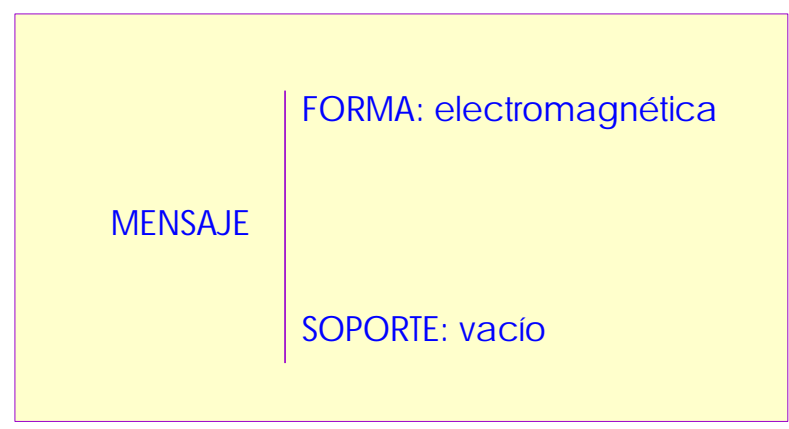

A partir de ahí, el proceso se establece en sentido inverso:

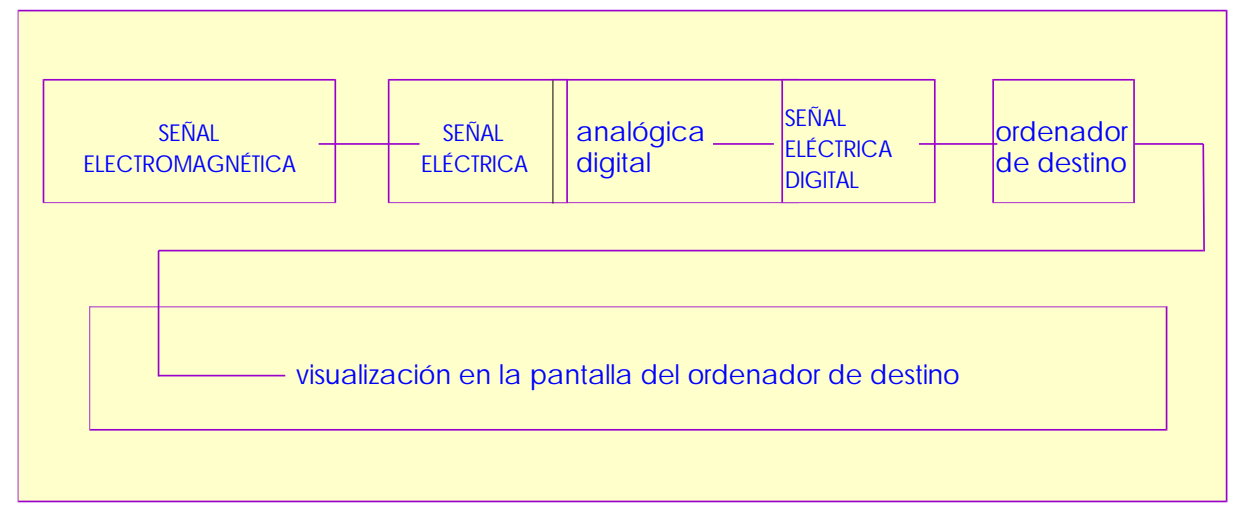

En resumen, el texto que "navega" permanentemente por las computadoras de todo el mundo sigue comportándose como un mensaje que constantemente precisa de un soporte para difundirse. La característica peculiar consiste en que el mismo mensaje modifica tanto su forma como la naturaleza del soporte al que se incorpora durante su difusión, mientras que en un "documento clásico" el soporte es único.

En consecuencia, en lo relativo al soporte, podemos englobar estas características del "documento clásico" y del "documento digital" al concebir el documento como "mensaje o mensajes icónicos o simbólicos, cada uno de ellos incorporado de modo permanente a un soporte". 


\section{InvetigaaónBiblictedógica v. 12 No. 25 julio/ diciembre de 1998}

El proceso observado con anterioridad, por el que un "documento digital" se difunde a través de redes telemáticas hasta computadoras espacialmente muy alejadas del que lo emitió, "y a la velocidad de la luz" en palabras de Negroponte, se explica bien gracias a esta versatilidad en la adopción de nuevas formas y soportes.

De la misma manera, esta propiedad explica por qué un "documento clásico" (un libro, por ejemplo) está limitado en su difusión espacial: la permanencia de forma y soporte impide su transformación a fin de ajustarse a los medios (redes de datos de gran capacidad y comunicación por satélite) que favorecerían su difusión.

La contrapartida de la difusión espacial se halla en la difusión temporal. Hoy por hoy, al menos, la forma y soporte del "documento clásico" (pienso en el papel) presenta ventajas indudables en cuanto a la difusión temporal (perduración del mensaje en condiciones aceptables de conservación), notablemente superior a la que presentan los "nuevos documentos".

\section{DOCUMENTO Y FINALIDAD}

Sin duda es la información -valor informativo- el rasgo distintivo esencial del documento que importa a la ciencia documental, pues convendremos en que su objetivo es la transmisión del conocimiento acumulado por el ser humano, cumpliendo de este modo una misión cultural y social decisiva. A este respecto Félix Sagredo Fernández y José María Izquierdo Arroyo afirman:

Un documento sólo existe cuando se utiliza como tal. Es decir, en sí es un objeto manufacturado y "mentefacturado" que puede funcionar como "documento" o como objeto arrojadizo. Es el "uso" lo que decide sobre su carácter documental. 9

En efecto, un cuadro o un monumento - como cualquier otro mensaje icónico- puede reportar al receptor el goce estético de su contemplación, y no sólo la información sobre las vestimentas o los materiales utilizados en una época concreta.

En definitiva, si es cierto que todo mensaje icónico o simbólico debe ser potencialmente considerado como un documento en cuanto que conlleva una información potencialmente útil para un receptor hipotético, también es cierto que esa potencialidad siempre latente debe desarrollarse y perfeccionarse con una predisposición también informativa en el observador, que debe acercarse al documento con la intención expresa de obtener algún conocimiento de él.

9 F. Sagredo Fernández y J. M. Izquierdo Arroyo. Concepiónlógicoling̈üstica delaDoumentadón Madrid: IBERCO M; RED COMNET DE LA UNESCO, 1983, p. 265. 
D eben excluirse, pues, en la definición de documento, aquellas actitudes limitadas a una percepción sensorial del objeto, y en general desestimar, por la parte que toca al receptor, cualquier talante suyo ajeno al estrictamente informativo. Esta observación ha de ser incluida en la definición de documento que propugnamos. Para ello, bastará añadir "empleados con una finalidad informativa".

\section{DEFINICIÓN DE DOCUMENTO}

Al reunir las características peculiares de los elementos componentes del documento deducidas hasta aquí, proponemos la siguiente definición de documento: Mensaje o mensajes i iónicos o simbólicos, cada uno de dlos inconparado pemanente mettea un sqparte, empleados con una finalidadinfomativa.

\section{ESQUEMA DEL DOCUMENTO}

A unque no todos los elementos que figuran han sido tratados en el presente trabajo, podemos resumir lo dicho hasta aquí en el siguiente esquema de documento:

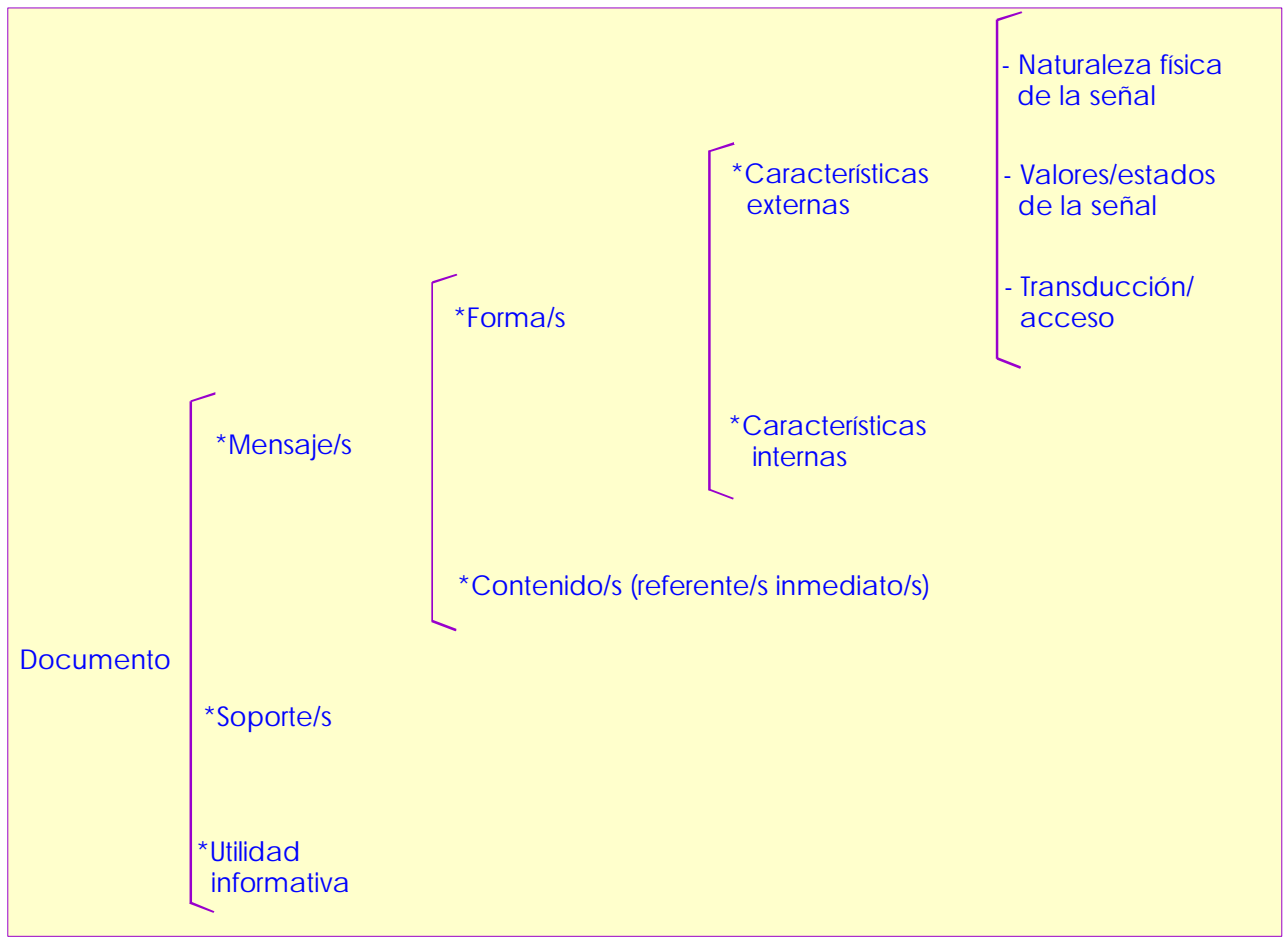

